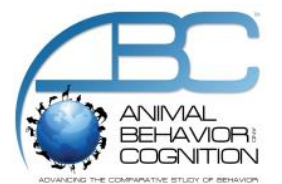

\title{
Aggressive Behaviors of Adult Male Atlantic Spotted Dolphins: Making Signals Count during Intraspecific and Interspecific Conflicts
}

\begin{abstract}
Cassandra L. Volker* \& Denise L. Herzing
Wild Dolphin Project and Florida Atlantic University

*Corresponding author (Email: cassiewdp@gmail.com)

Citation - Volker, C. L., \& Herzing, D. L. (2021). Aggressive behaviors of adult male Atlantic spotted dolphins: Making signals count during intraspecific and interspecific conflicts. Animal Behavior and Cognition, 8(1), 36-51. https://doi.org/10.26451/abc.08.01.04.2021

Abstract - Some species exhibit behavioral plasticity by altering their aggressive behavior based on their opponent. Atlantic spotted dolphins (Stenella frontalis) and bottlenose dolphins (Tursiops truncatus) are two sympatric species resident to the northern Bahamas. We examined whether groups of adult male spotted dolphins demonstrated behavioral plasticity during two different types of aggressive interactions. We described and compared the types of aggressive behaviors used during intraspecific aggression and interspecific aggression with bottlenose dolphins. Between the years 1991-2004, twenty-two aggressive encounters (11 intraspecific (spotted only), 11 interspecific (spotted vs. bottlenose)) were behaviorally analyzed. Twenty-three specific aggressive Behavioral Events, further grouped into three Behavioral Types, were examined throughout these encounters. Similarities and differences in the use of the Behavioral Types occurred during intra- and interspecific aggression. Groups of male Atlantic spotted dolphins altered their behavior during aggressive encounters with male bottlenose dolphins. Spotted dolphins increased their use of the Pursuit Behavioral Type and did not use the Display Behavioral Type significantly more than the Contact Behavioral Type during interspecific aggression. The increased use of a more overt and energy intensive Behavioral Type, Pursuit, suggests that Atlantic spotted dolphins altered their behavior during aggressive encounters with bottlenose dolphins to compensate during fights with a larger species and/or to effectively communicate with a different species.
\end{abstract}

Keywords - Sympatric, Stenella frontalis, Tursiops, spotted dolphin, aggression, Bahamas

Aggression is defined as behavioral displays and physical attacks that occur in the context of competition over resources (Grether et al., 2013) and/or societal dominance/rank (Muller, 2002). Aggressive behavior has been observed in a variety of social species, such as dolphins (Stenella frontalis and Tursiops truncatus; Connor et al., 2005; Herzing et al., 2003), chimpanzees (Pan troglodytes; Wilson \& Wrangham, 2003), and different species of birds (Arnold, 2000; Dow, 1977).

Intraspecific aggression, between members of the same species, and interspecific aggression, between members of different species, are often observed throughout the animal kingdom. Both types of aggression frequently stem from competition over food (Glova, 1986; Shane, 1996), space (Ewald \& Bransfield, 1987; Mitani et al., 2010), and survival (Coscarella \& Crespo, 2010; Huber \& Brennan, 2011). Among dolphins, intraspecific aggressive interactions can also occur during competition over mates (Connor et al., 1992) and while protecting young from intraspecific infanticide (Robinson, 2014). Interspecific aggressive interactions can also be a mechanism of reproductive isolation to prevent hybridization when two species live sympatrically and both geographical and mechanical forms of isolation are absent (Cusick \& Herzing, 2014). Some common behaviors observed during both intra- and interspecific dolphin aggression are as follows: tooth-raking, head-slaps, tail-slaps, chasing, aerial leaps, 
jaw clapping, open mouth gestures, head-jerking, and biting (Connor et al., 1992, 2005; Coscarella \& Crespo, 2010; Kurimoto, 2003; Parsons et al., 2003; Psarakos et al., 2003; Shane, 1996).

In the Bahamas, the sympatric Atlantic spotted (Stenella frontalis) and bottlenose (Tursiops truncatus) dolphins are known to travel and forage together but they also engage in aggressive interactions (Cusick \& Herzing, 2014; Herzing \& Johnson, 1997). From 1985 to 2001, there were a total of 1,899 encounters and $15 \%$ of these encounters were interspecific in nature (Herzing \& Johnson, 1997). Of this $15 \%$ concerning interspecific encounters, $35 \%$ of the encounters were aggressive (Herzing \& Johnson, 1997). This specific spotted dolphin community is known to communicate by using a diverse aggressive behavioral repertoire. During both intra- and interspecific aggression, aggressive behaviors can include head-to-head posturing, open mouth displays, tail and jaw smacking, body charging, torus bubble displays, and the pinning of an individual on the sea floor (Herzing, 1996, 2000; Herzing \& Johnson, 1997).

During interspecific aggression with the bottlenose dolphins some complex factors are introduced. For one, the spotted dolphins are smaller than the bottlenose dolphins. The spotted dolphins are about one meter smaller in length and weigh anywhere from 220-315 lbs (NOAA, n.d.) whereas the bottlenose dolphins can weigh anywhere from 300-1,400 lbs (NOAA, n.d.). Bottlenose dolphins in the Bahamas are closer to the 300-500 $\mathrm{lb}$ range, which means that they can weigh on average 100-200 lbs more than the spotted dolphins. Aside from the size difference, male bottlenose dolphins will often sexually harass male spotted dolphins in the form of side-mounting behavior. During side-mounts, usually one or more male bottlenose dolphins try to force their erect penis into the genital slit of the male spotted dolphin (Herzing, 1996; Herzing et al., 2003; Herzing \& Johnson, 1997). This side-mounting behavior is believed to be a type of dominance display that the bottlenose dolphins are exerting on the spotted dolphins (Herzing \& Elliser, 2013).

Most likely as a result of the size difference between the two species, Herzing and Johnson (1997) found that the ratio of spotted dolphins to bottlenose dolphins determined the success of the spotted dolphins during interspecific aggression. Success was determined by the cessation of side-mount activity followed by a spotted dolphin chase to force the bottlenose dolphin out of the area. Six spotted dolphins to one bottlenose dolphin was the necessary ratio needed to successfully cease or prevent sexual harassment (Herzing \& Johnson, 1997). In a later study conducted by Cusick and Herzing (2014), the synchronous state of the spotted dolphin coalition was also beneficial during interspecific aggression. According to these two studies, larger group sizes and more synchronous behaviors helped spotted dolphins during aggression with the larger bottlenose dolphins.

Observations have been made in both chimpanzees and avian species that different aggressive tactics are used contingent upon the opponent. One example from the Class Aves that illustrates differences during intraspecific and interspecific aggression is the noisy miner (Manorina melanocephala). Noisy miners are known for their mobbing defense tactic and have been discovered to have different mobbing strategies depending on the intruder (Arnold, 2000; Dow, 1977). Arnold (2000) has observed up to one hundred noisy miners involved together in a single mobbing of a large predator such as a raptor. When fighting conspecifics, however, the males form smaller coteries with neighboring males at bordering regions to fend off other males (Dow, 1979).

Chimpanzees also display different aggressive behavioral styles. Chimpanzees fight within their own group (intragroup) and also fight different communities of chimpanzees (intergroup) (Kaburu et al., 2013; Mitani et al., 2010; Wilson \& Wrangham, 2003). Intergroup aggression often only happens between males, and results in severe if not lethal injuries to the throat, removal of some, if not all of the genitalia, disfiguring of the face, and broken bones (Kaburu et al., 2013; Wilson \& Wrangham, 2003). Since only four cases of lethal violence were reported during intragroup aggression during decades when frequent observations occurred, it is suggested that intragroup inflicted injuries are less severe than intergroup inflicted injuries (Kaburu et al., 2013).

\section{Current Study}

Knowing that birds and chimpanzees can change their aggressive tactics, the main objective of this study was to assess whether groups of spotted dolphins altered their use of specific types of aggressive 
behaviors based on their opponent. The Wild Dolphin Project's study site, in the Bahamas, provides a unique opportunity to study such behavioral plasticity in wild dolphins underneath the water. We examined three types of aggressive behaviors used by Atlantic spotted dolphin groups during interspecific and intraspecific aggression: Contact, Pursuit, and Display Behavioral Types. In addition to exploring how the Atlantic spotted dolphins use aggressive signals, it is interesting to analyze how similar or dissimilar their visual communication signals in general might be during these interactions.

\section{Method}

\section{Study Site}

The study site for the Wild Dolphin Project is located on the western edge of Little Bahama Bank (LBB) off Grand Bahama Island in the Bahamas (Figure 1). The field site encompasses an area about 480 $\mathrm{km}^{2}$ in size on the northwest edge of Little Bahama Bank. This area is composed of clear, shallow water with depths ranging from 6-16 m, and an average visibility of up to $9 \mathrm{~m}$. These conditions provide an ideal study site for underwater observation of dolphin behavior.

\section{Figure 1}

The Wild Dolphin Project's study site on Little Bahama Bank, Grand Bahama Island, the Bahamas

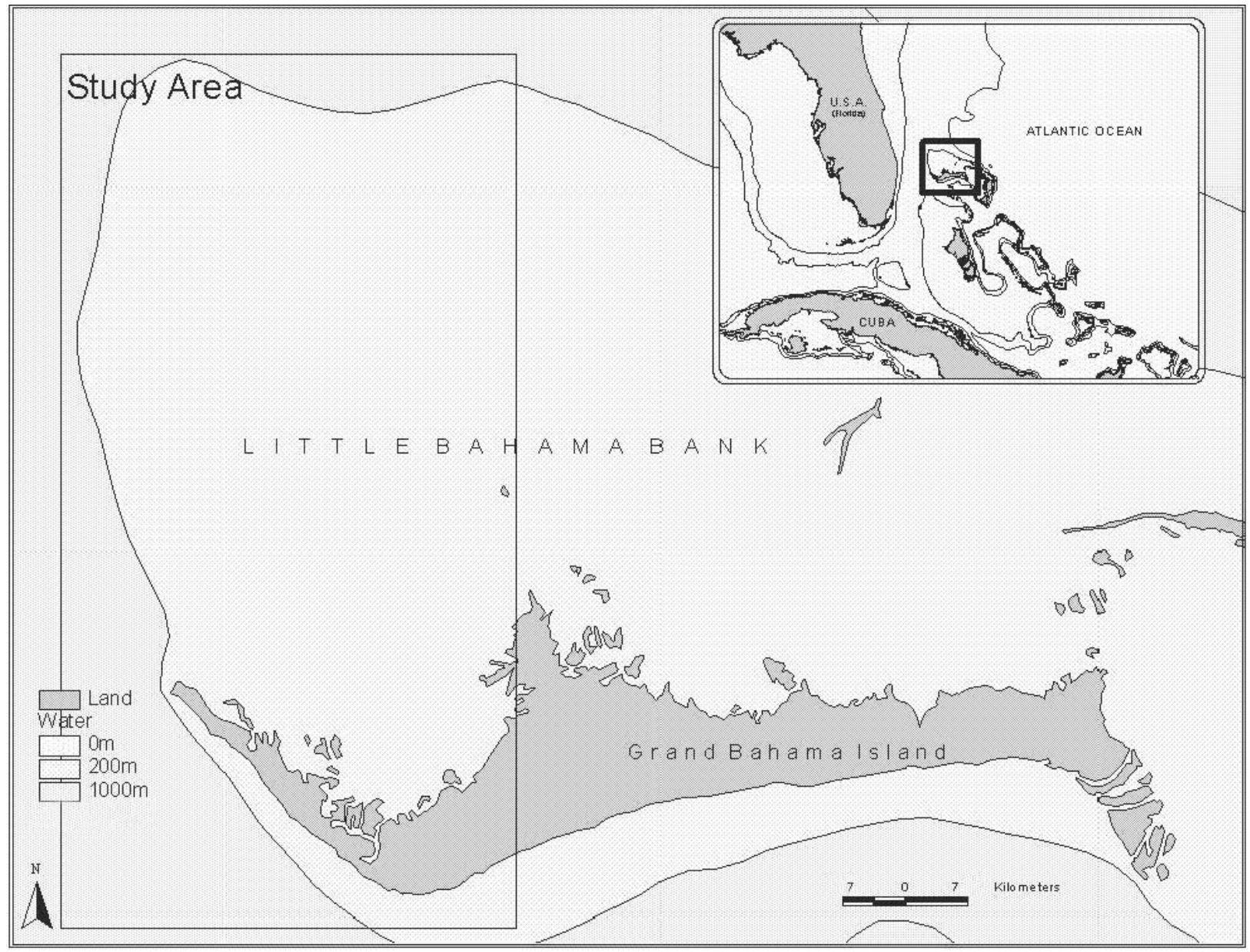




\section{Study Population}

Since 1985, the Wild Dolphin Project has collected underwater data from two resident sympatric dolphin species. During any given season, community size averages 100 Atlantic spotted dolphins and 100 Atlantic bottlenose dolphins in the study area. Data collected on both species included individual identification, age (Herzing, 1997), gender, maternal relationships (Bender et al., 2009; Herzing \& Brunnick, 1997), social behaviors (Elliser \& Herzing, 2015; Herzing \& Johnson, 1997) and vocalizations (Au \& Herzing, 2003; Herzing, 1996, 2004).

Atlantic spotted dolphins have four age classes described in Herzing (1997): two-tone, speckled, mottled, and fused. Younger juvenile males often exhibit play aggression, which was not the focus of this study. Therefore, this current study focused only on the aggressive behaviors of young adult and adult male Atlantic spotted dolphin groups, that included the mottled (8-15 years) and fused (15 years and older) age classes (Herzing, 1997).

Only a small number of underwater observations of bottlenose dolphin intraspecific aggressive encounters have been collected by the Wild Dolphin Project over the decades. Therefore, we focused on comparing only the spotted dolphin behavior during intra- and interspecific aggression.

\section{Behavioral Definitions}

\section{Defining Aggression, Intra- \& Interspecific}

Aggression was defined as multiple behavioral displays and physical attacks, previously designated as aggressive by the Wild Dolphin Project, that occurred during an encounter (Table 1). The behaviors seen in Table 1 were observed frequently during aggressive encounters on LBB and have also been observed in other delphinid aggressive interactions (Connor et al., 1992, 2005; Coscarella \& Crespo, 2010; Herzing, 1996, 2000; Herzing \& Johnson, 1997; Kurimoto, 2003; Psarakos et al., 2003; Shane, 1996).

Intraspecific aggressive behaviors were defined as aggressive acts directed towards individuals of the same species, whereas interspecific aggressive behaviors were directed towards individuals of another species (in this case, bottlenose dolphins). An intra- or interspecific aggressive encounter was defined as multiple intra- or interspecific aggressive behaviors that occurred during a period of time.

\section{Defining Specific Behavioral Types and Events (Ethogram)}

An ethogram was developed in which aggressive activities were scored as single events in time (Behavioral Events; e.g., open mouth, head to head). Refer to Table 1 for the ethogram of the 23 Behavioral Events further clustered into three Behavioral Types (Contact, Pursuit, and Display). 
Table 1

Behavioral Ethogram showing the Behavioral Types and Behavioral Events within those Types

\begin{tabular}{|c|c|c|}
\hline Behavioral Types & Behavioral Events & Description \\
\hline \multicolumn{3}{|l|}{ Display } \\
\hline & Arch & $\begin{array}{l}\text { Dolphin(s) body is in a crescent shape, usually stationary, but mouth may be open } \\
\text { and pectoral fins may be moving. }\end{array}$ \\
\hline & S posture & Dolphin(s) body is arched so that rostrum is up, body is down, and flukes are up. \\
\hline & Bout of Head to head & $\begin{array}{l}\text { Dolphin(s) orients its head to the head of another dolphin(s) for } 3 \text { or more s. Can be } \\
\text { in motion or stationary position. }\end{array}$ \\
\hline & Brief Head to head & $\begin{array}{l}\text { Dolphin(s) orients its head to the head of another dolphin(s) for less than } 3 \mathrm{~s} \text {. Can be } \\
\text { in motion or stationary position. }\end{array}$ \\
\hline & Jaw clap & Dolphin(s) may open and shut jaw(s) rapidly, directed at a dolphin(s). \\
\hline & Jerk & Dolphin(s) moves head horizontally in quick motion, usually to one side. (Or) \\
\hline & & Dolphin moves body side to side. \\
\hline & Bubbles & $\begin{array}{l}\text { Dolphin(s) creates bubble ring underwater, which floats towards surface. } \\
\text { (Or) Dolphin(s) produces a burst of bubbles. }\end{array}$ \\
\hline & Tail Cavitation & Dolphin(s) slams tail making a large bubble formation. \\
\hline & Breach & Dolphin(s) leaps out of the water. \\
\hline & Inverted posture & Dolphin(s) is turned upside down, but does not have to be chasing or swimming. \\
\hline & Passive & Dolphin(s) lies still in the water column while not moving. \\
\hline & Open mouth & Dolphin(s) displays with mouth open directed at another dolphin(s). \\
\hline & Perpendicular Pass & Dolphin(s) swims straight across and in front of a dolphin(s). \\
\hline & Spin & Dolphin(s) turns on its horizontal axis underwater. \\
\hline \multicolumn{3}{|l|}{ Pursuit } \\
\hline & Chase & Dolphin(s) pursues another dolphin. \\
\hline & Follow & Dolphin(s) slowly swims with or trails another dolphin(s). \\
\hline \multicolumn{3}{|l|}{ Contact } \\
\hline & Charge & $\begin{array}{l}\text { One or more individuals swim directly at another individual(s). May or may not } \\
\text { make contact. }\end{array}$ \\
\hline & Hold down & Dolphin, or group of dolphins, restrains another dolphin(s) on the bottom. \\
\hline & Bite & $\begin{array}{l}\text { Dolphin(s) clamps jaws down on or rakes with its teeth on any part of the body of } \\
\text { another dolphin(s). }\end{array}$ \\
\hline & Tail slap & Dolphin(s) strikes another dolphin with its tail. \\
\hline & Push & Dolphin(s) shoves another with rostrum or other body part. \\
\hline & Rolling & Dolphin(s) tussling in a tight ball, hard to differentiate behaviors. \\
\hline & $\begin{array}{l}\text { Actively Avoiding } \\
\text { Side-mounting }\end{array}$ & $\begin{array}{l}\text { Dolphins(s) are swimming away or fighting to get free of being side-mounted by } \\
\text { bottlenose dolphins. }\end{array}$ \\
\hline
\end{tabular}

\section{Data Collection - In the Field}

Since 1985, the Wild Dolphin Project has collected video and photographic data on wild Atlantic spotted and bottlenose dolphins during every summer (May - September) from 0700 to 1900 daily aboard $\mathrm{R} / \mathrm{V}$ Stenella (a 20-m live-aboard catamaran). An encounter is composed of in-water observations of spotted dolphins, bottlenose dolphins, or both where videography, photography, and/or human observation were used to document behavior. An encounter, the sample unit for this study, starts when underwater video observation of the dolphins begins and ends when the underwater video observation ends. Information was recorded during the encounter using various underwater video cameras to document behaviors (e.g., $8 \mathrm{~mm}$, Hi 8mm, High def), with attached hydrophone to record vocalizations (Herzing, 1996). Ad lib, focal sampling, and behavioral event scanning methods were used to collect the video data (Herzing, 1996; Herzing et al., 2003).

\section{Video Selection from the Wild Dolphin Project Database}

For this study, archival underwater video encounters were selected between the years 1991-2004 from the Wild Dolphin Project long-term database. Twenty-two videos were extracted, 11 inter- and 11 intraspecific aggression. The video recordings were continuous during any given encounter and varied in 
range from $5 \mathrm{~min} 35 \mathrm{~s}$ to $21 \mathrm{~min}$ and $30 \mathrm{~s}$. Smaller clips of behavioral samples that were of sufficiently high resolution, clear, and followed the group were extracted for analysis. The data analyzed consisted of $75 \mathrm{~min}$ and $41 \mathrm{~s}$ of intraspecific aggression obtained from 11 separate intraspecific aggressive encounters along with $106 \mathrm{~min}$ and $29 \mathrm{~s}$ of interspecific aggression obtained from 11 separate interspecific aggressive encounters.

Aside from sufficient resolution the videos also needed to follow these selection criteria: 1) the videos needed to contain mostly young adult and adult male spotted dolphin groups, which included the mottled and fused age classes, and adult male bottlenose dolphins for interspecific encounters; 2) when a juvenile of either species was present, they must not have been involved in the aggression or had very minimal involvement; 3 ) and lastly a focal group, or one Atlantic spotted dolphin coalition that was most consistently videotaped, needed to be differentiated adequately throughout the video.

\section{Video Analysis Procedure}

Version 7.0 of The Observer XT (2012) behavioral software was used for simultaneous behavioral coding and scoring with integrated video media. Behaviors were coded into the Observer XT software to score the intra- and interspecific aggressive activity.

Continuous behavioral event sampling was used to watch and score every occurrence of the individual Behavioral Events in the ethogram performed by the focal group. Data recordings were continuous throughout the entire aggressive encounter clip. Every occurrence of the Behavioral Events, within the three Behavioral Types (Contact, Pursuit, and Display), performed by the focal group were recorded.

During intraspecific aggression, there were bouts of time where deciphering the focal group was not possible due to video quality and the dispersal of individuals. During these times, there were Behavioral Events that could not be attributed to the focal group. As a result, all of the statistical test results were analyzed only from bouts of time where the focal group could be deciphered, totaling $75 \mathrm{~min}$ and $41 \mathrm{~s}$ mentioned previously. Only these bouts of time were used because the Behavioral Events scored were attributed to the same focal group throughout an entire encounter and thus were consistent.

As with other social species, it is not always possible to follow one individual during social activities (Slotow, 1996). Likewise, we were not able to track an individual dolphin out of a larger coalition, so focal group follows were scored instead of individual focal follows. As a result, these data are subject to problems with pseudoreplication. To reduce the effects of pseudoreplication, no two encounters from the same day were used with one exception: there was one day where one encounter was intraspecific aggression while the other was interspecific aggression. Due to the shift in species interaction these were scored as independent samples. The encounters used were also sampled across multiple years to cover a wider range of behavior possibilities. Should new technology arise that allows a visible tracker on an individual during a video sequence, an individual could be followed.

To ensure intra-rater reliability, $20 \%$ of the intraspecific encounter videos $(N=2)$ and $20 \%$ of the interspecific encounters $(N=2)$ were scored two times by the primary observer. To ensure strong interrater reliability, two of the intra- and two of the interspecific encounter videos were re-coded by a second trained observer to compare to the primary observer's code. The encounters used to check intra- and interrater reliability were randomly generated using random.org.

To calculate between and within-observer reliability, a Pearson's r correlation was calculated using the reliability statistical analysis program in Observer XT (Martin \& Bateson, 2007) with a set 1second tolerance window. A correlation value of .70 or greater was considered to be strong intra- and inter-rater reliability; all reliability testing results were above .70 .

\section{Statistical Analyses/Preparing Data for Analysis}

Before any statistical analyses were run, normality and homogeneity of variances were analyzed to determine whether or not a parametric or non-parametric test was needed. The significance value for all 
the statistical tests was set at $p<.05$ and the tests were all two-tailed, unless specified otherwise. All statistical tests were performed in IBM SPSSv22 statistical software.

\section{Group Size}

The video clips used for this study had different group sizes both between and within intra- and interspecific aggression. Throughout the 22 encounters, group size varied from as low as two individuals to as high as 24 individuals.

In order to determine that group size did not significantly affect the encounter behavioral rate per minute (total Behavioral Event frequency/duration of observation) for each type of aggression, the data were split into encounters with six or less individuals or greater than six individuals. The number six was chosen because this number of spotted dolphins has been shown to be a factor during aggression with this community before (Herzing \& Johnson, 1997). A Mann-Whitney U test was used to analyze this data: group size was the independent variable and encounter behavioral rate was the dependent variable.

\section{Behavioral Event/Type Standardization}

A total of 23 different Behavioral Events, within the three Behavioral Types, were recorded throughout the 22 encounters and were scored individually. Frequencies of each Behavioral Event were collected during each encounter. Because the video clips were different time lengths, the Behavioral Events/Types were divided by time to standardize these data to allow for comparison of rates of Behavioral Events/Types. The frequency of a Behavioral Event was divided by the duration of observation (in minutes) to estimate the Behavioral Event rate per minute (rpm).

Behavioral Type rate per minute was calculated by totaling the frequencies of all the Behavioral Events within a Behavioral Type and then dividing by the duration of observation. Lastly, the sum of all the individual Behavioral Event frequencies was divided by the duration of observation to get a total rate per minute of aggressive behaviors performed during an encounter.

\section{Statistical Tests}

\section{Behavioral Events}

Typical descriptive statistics were run for the individual Behavioral Events such as obtaining the average rate per minute that each Behavioral Event was used during each type of aggression. Also, whether or not a Behavioral Event was used solely in one type of aggression was reported.

\section{Total Encounter Behavioral Rate Per Minute}

A Mann-Whitney U test examined if there was a significant difference in the encounter behavioral rate between inter- and intraspecific aggression: the independent variable was type of aggression (inter- vs. intra-) and the dependent variable was encounter behavioral rate.

\section{Behavioral Type Comparisons}

\section{Behavioral Type use Between Inter- and Intraspecific Aggression}

Three separate Mann-Whitney U tests were performed to evaluate significant differences in the Behavioral Type rates between interspecific and intraspecific aggression: the independent variable for these tests was type of aggression (inter- vs. intra-) and the dependent variable was Behavioral Type rpm (Contact, Pursuit, Display). 


\section{Behavioral Type use Within Inter- and Intraspecific Aggression}

Two separate Friedman tests were performed to evaluate specific differences in Behavioral Type rates within each aggression type (intraspecific, interspecific): the independent variable for these tests was Behavioral Type (Contact, Pursuit, Display) and the dependent variable was Behavioral Type rpm. Analyses were performed separately for interspecific and intraspecific aggression, each with follow up Sign tests as post hoc tests to assess significant differences. A Bonferroni was applied to the Sign tests to address the implications of running multiple tests $(p=.017)$.

\section{Results}

In total there were 1,550 encounters recorded by the Wild Dolphin Project during the years 1991 to 2004 on Little Bahama Bank in the Bahamas. Intraspecific encounters (spotted dolphins only) encompassed $75.78 \%$ of the total, and intraspecific aggression was observed in $9.86 \%$ of these encounters. Interspecific encounters (spotted and bottlenose dolphins), accounted for $14.7 \%$ of the total encounters throughout the same time span, and interspecific aggression occurred during $45.2 \%$ of those encounters.

\section{Group Size Analysis}

Group size did not have a significant effect on the encounter behavioral rates for either inter- $(U=$ $10, p=.361)$ or intraspecific aggression $(U=10, p=.683)$. Therefore, the 11 intraspecific encounters and the 11 interspecific encounters could be combined and analyzed as two separate groups.

\section{Comparing Intraspecific and Interspecific Aggression}

\section{Total Encounter Behavioral Rate Per Minute}

When examining all of the Behavioral Events combined for the encounter behavioral rate, there was no significant difference in the average behavioral rate between inter- and intraspecific aggression $(U$ $=56.000, p=.797)\left(\mathrm{M}_{\text {inter }}=8.12, \mathrm{M}_{\text {intra }}=7.60\right.$, Figure 2$)$.

\section{Figure 2}

Average rate per min for all Behavioral Events Combined During the Encounters for both Intraspecific and Interspecific Aggression

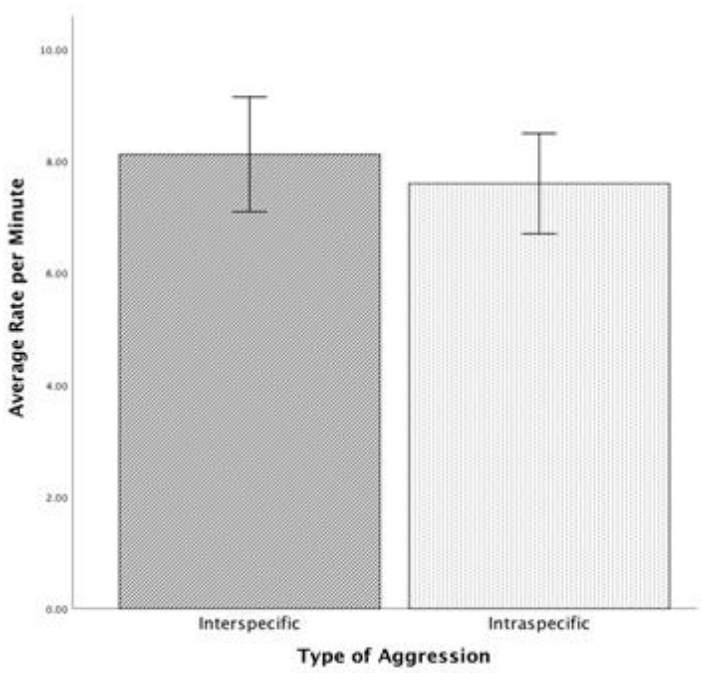

Note. The Interspecific average behavioral rate is represented with black diagonal stripes, and intraspecific is represented with black dots. Overall, when the average behavioral rates were compared, there was no significant difference between inter- and intraspecific aggression. Error bars indicate $+/-S E$. 


\section{Behavioral Types}

The three Behavioral Types were utilized in the same frequency pattern during both inter- and intraspecific aggression. Display had the highest average rate per minute (rpm) of use $\left(M_{\text {inter }}=4.26, M_{\text {intra }}\right.$ $=5.49)$, followed by Contact $\left(\mathrm{M}_{\text {inter }}=2.45, \mathrm{M}_{\text {intra }}=1.78\right)$, while Pursuit had the lowest average rpm $\left(\mathrm{M}_{\text {inter }}\right.$ $=1.42, \mathrm{M}_{\text {intra }}=0.33$ ).

When comparing the average rpm for the Behavioral Types between inter- and intraspecific aggression, Mann-Whitney $U$ tests revealed that the Pursuit Type was used significantly more during interspecific aggression than during intraspecific aggression $(U=9, p=.001$, Figure 3$)$. There was no significant difference in the use of either the Display $(U=40, p=.178)$ or Contact $(U=37, p=.123)$ Behavioral Types between aggression types (Figure 3).

For interspecific aggression, the Friedman test was significant $\left(\chi^{2}(2, N=11)=16.545, p<.001\right)$ and the post hoc exact Sign tests showed that both the Display and Contact median rates per minute of use were significantly higher than the Pursuit (Display vs. Pursuit, $p=.001$; Contact vs. Pursuit, $p=.012$ ). However, between Display and Contact there was no significant difference $(p=.065$, Figure 3$)$.

For intraspecific aggression, the Friedman test was also significant $\left(\chi^{2}(2, N=11)=22.00, p<\right.$ $.001)$ and the post hoc exact Sign tests revealed that all three Behavioral Types elicited significantly different medians. The Display median rate per minute of use was significantly higher than both Contact $(p=.001)$ and Pursuit $(p=.001)$, and Contact's median rate per minute of use was significantly higher than Pursuit's ( $p=.001$, Figure 3).

\section{Figure 3}

Mean Rate per Minute that each Behavioral Type was Used During both Interspecific and Intraspecific Aggression

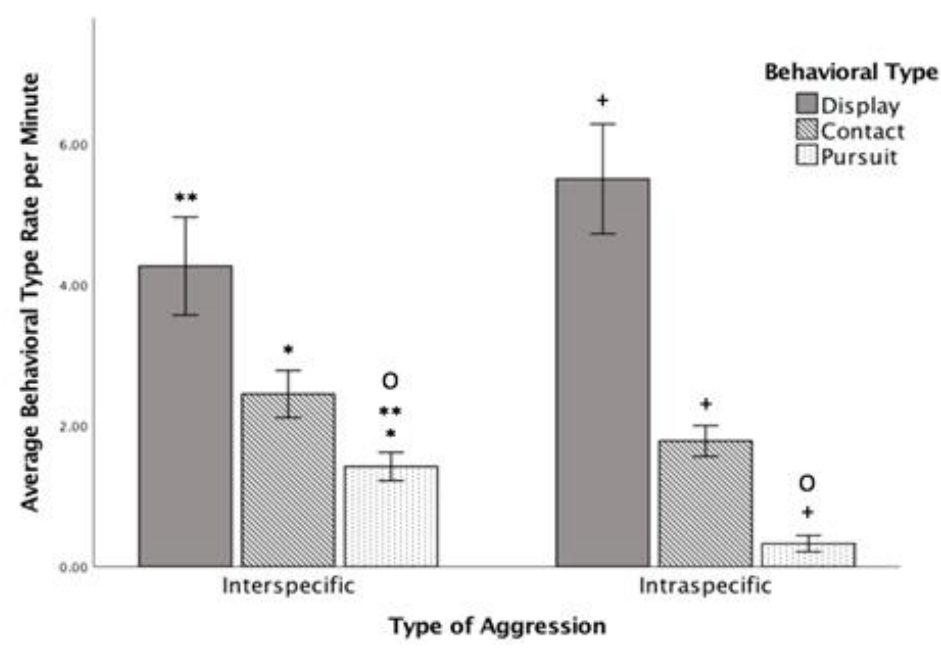

Note. The only Behavioral Type that significantly differed in rate of use between the two types of aggression was the Pursuit Behavioral Type, designated by the $(\mathrm{O})$. The Pursuit Behavioral Type was used significantly more during interspecific aggression than intraspecific aggression. This graph also shows that during interspecific aggression, both the Display and Contact Behavioral Types were used significantly more than the Pursuit, designated by the (*) for the significant difference between Pursuit and Contact, and designated by the (**) for the significant difference between Pursuit and Display. For intraspecific aggression, all three Types differed significantly from each other, designated by the (+). Error bars indicate $+/-S E$.

\section{Individual Behavioral Events}

The following individual Behavioral Events had the highest average rates per min during both intra- and interspecific aggression: charge (Contact), brief head-to-head (Display), and open mouth (Display) (Figure 4). Out of the total 23 Behavioral Events: three were only observed during interspecific 
aggression (actively avoiding side-mounting, passive, tail cavitation), while two were only observed during intraspecific aggression (s-posture, spinning, Table 2).

\section{Figure 4}

Average Rate per Minute that each Behavioral Event was Observed During both Interspecific and Intraspecific Aggression

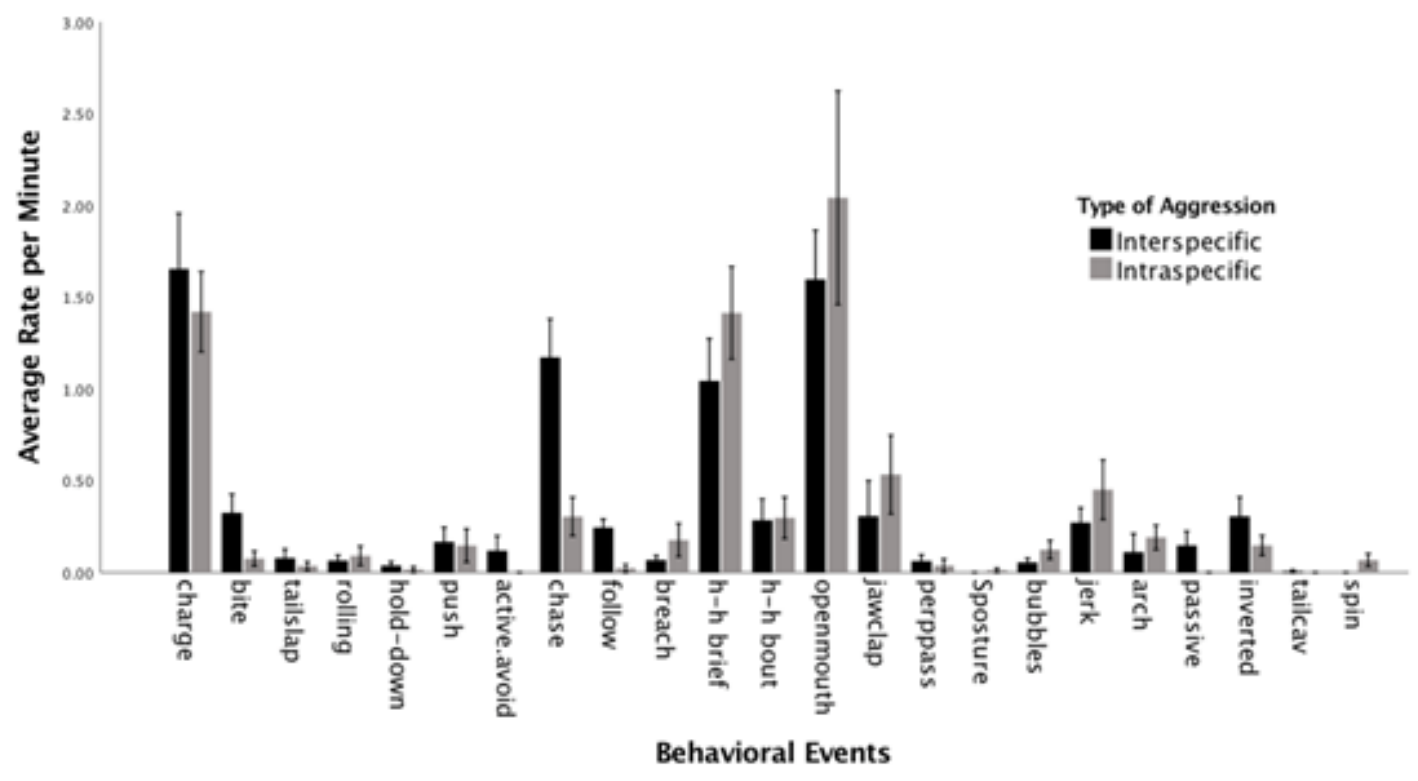

Note. Interspecific is designated by the black bars and intraspecific is designated by the grey bars. h-h represents head-to-head, perp pass represents perpendicular pass, and active avoid represents actively avoiding side-mounting. Error bars indicate $+/-\mathrm{SE}$.

Table 2

Behavioral Events Observed During Either both types of Aggression, only Interspecific, or only Intraspecific

\begin{tabular}{c|c|c}
\hline Interspecific \& Intraspecific & Interspecific & Intraspecific \\
\hline Arch & Actively Avoiding Side-mounting & Sposture \\
Bout of H-H & Tail Cavitation & \\
Brief H-H & & \\
Jaw Clap & & \\
Jerk & & \\
Bubbles & & \\
Breach & & \\
Inverted Posture & & \\
Open Mouth & & \\
Perpendicular Pass & & \\
Chase & & \\
Follow & & \\
Charge & & \\
Hold Down & & \\
Bite & & \\
Tail Slap & & \\
Push & & \\
Rolling & & \\
\hline
\end{tabular}

Note. H-H represents Head-to-Head. 


\section{Discussion}

The present study found similarities and differences among the Behavioral Types and individual Behavioral Events that groups of Atlantic spotted dolphins used during intra- and interspecific aggressive encounters. The similarities were on par with evolutionary trends, while the differences have raised some interesting questions and avenues for future research.

\section{Intra- and Interspecific Aggression- Behavioral Events}

During both inter- and intraspecific aggression, there was no significant difference in the overall average behavioral rate (rpm) for Behavioral Events used by spotted dolphins: they did not use significantly more aggressive Behavioral Events during either type of aggression.

In total, 23 different individual Behavioral Events were used by spotted dolphin groups during aggression. Eighteen of the Behavioral Events were utilized during both inter- and intraspecific aggression. The other five Behavioral Events were only recorded in one type of aggression (Table 2). The same three Behavioral Events, "charge," "head-to-head brief," and "open mouth," were used the most during both types of aggression; and these three behaviors, among others, have also been observed in bottlenose dolphin aggression (Herzing, 1996; Robinson, 2014; Weaver, 2003). The presence and use of similar aggressive behaviors between these two species are not too surprising. The bottlenose and spotted dolphin have the same streamlined body anatomy limiting the ways in which they can contort and manipulate their bodies resulting in repetition of behaviors (Psarakos et al., 2003). Aside from the streamlined body shape, genetics and similar social structures may also explain the similarities in behaviors utilized during aggression. These species are closely related genetically. According to LeDuc et al. (1999), this species of spotted dolphin is more closely related to bottlenose dolphins than to others of their same genus. Lastly, these two sympatric species have similar social dynamics and with overlapping territories they have a lot of exposure to one another growing up. Some similar social dynamics include living in fission-fusion societies, males form tight bonds, and females often associate based on reproductive status (Elliser \& Herzing, 2012; Herzing \& Brunnick, 1997; Rogers et al., 2004).

A total of 14 different display Behavioral Events from the Display Behavioral Type were observed during aggression for the Atlantic spotted dolphin. The Display Behavioral Type also had the highest number of individual Behavioral Events and was used the most on average compared to Contact and Pursuit. This is not unreasonable because individuals usually try to deter the enemy by displaying first to avoid wasting energy and also decreasing the chance of injury, which will be talked about later in this discussion. A large repertoire of Display behaviors can be advantageous for a species. The "graded signal hypothesis" (Van Rhijn, 1980) might provide a possible explanation for the variety of Display behaviors in this community. Graded signals are warnings that increase in strength and signify more serious repercussions if the enemy does not back down (Van Rhijn, 1980). It has been found in song sparrows (Melospiza melodia) that song type matching is an honest early threat signal that predicted subsequent escalated signals such as soft songs and wing waves (Akçay et al., 2013). Depending on the situation or opponent, the spotted dolphins appear to have a large repertoire of Display behaviors to choose from during confrontations. A larger repertoire could possibly afford spotted dolphins different ways they can avoid energy costly and risky attack behaviors. The observation of more Display behaviors may represent "graded signaling" in this community, but more detailed analyses of behavioral sequences and the likelihood of attack following these behaviors are needed.

\section{Intra- and Interspecific Aggression- Behavioral Types}

This community of spotted dolphins utilized the three Behavioral Types in the same overall pattern during both intra- and interspecific aggression: Display had the highest mean rate per minute (rpm), followed by Contact, and the Pursuit Behavioral Type had the lowest mean rpm. Evolutionarily, Display behaviors are considered to be less energetically costly and less risky than Contact and Pursuit behaviors. This would potentially explain why the spotted dolphins utilized their Display behaviors the 
most. Used by many species, threat displays (termed the "Display Behavioral Type" in this paper) serve to communicate intentions (Cullen, 1966; Van Rhijn, 1980), and can be used to solve conflicts before they escalate into full-blown physical attacks (Clutton-Brock et al., 1979; Geist, 1965; Waas, 1991). Red deer (Cervus elaphus L.) exhibit a whole series of displays, such as roaring and parallel walking (Bützler, 1974). African lions (Panthera leo; Heinsohn, 1997) and black howler monkeys (Alouatta caraya; Byrne $\&$ da Cunha, 2006) roar or howl to try and settle conflicts without further aggressive action by judging the size of the enemy based on the noise. Roaring and howling displays, among others, can deter the enemy without a potentially costly physical fight, which would reduce unnecessary energy expenditure and the chance of injury or even death.

When the Behavioral Types were examined separately within each type of aggression, some differences were also seen. During intraspecific aggression the spotted dolphins used Displays significantly more than Contacts, but during interspecific aggression these two Types were not used significantly differently. The bottlenose dolphins are larger than the spotted dolphins, and thus, strength in numbers plays a vital role for the spotted dolphins during interspecific encounters as well. Herzing and Johnson (1997) reported that spotted dolphins needed to have at least a six to one ratio over the bottlenose dolphins to move the aggression in their favor. Spotted dolphins may use significantly less Contact behaviors than Display behaviors during intraspecific aggression to reduce the risk of injury to their fellow coalition mates whom they may need to help fight the larger bottlenose dolphins in other aggressive encounters.

Chimpanzees have also been shown to decrease severity during aggression with coalition mates. When chimpanzees fight others within their own group, the aggression is not as extreme and there are fewer fatalities than when they fight a different group of chimpanzees (Kaburu et al., 2013; Wilson \& Wrangham, 2003). One reason for the decreased severity when fighting others of the same group can be due to the fact that chimpanzees use strength in numbers to their advantage and often gauge their probability of success on the numerical strength of their opponent (Boesch \& Boesch-Achermann, 2000; Kaburu et al., 2013; Wilson et al., 2002; Wilson \& Wrangham, 2003).

Observations of dolphin interspecific aggression in the Bahamas provides an example of a more energy costly Behavioral Type, Pursuit, being used more during interspecific aggression. As previously mentioned, Contact and Pursuit behaviors can be more energy costly and risky behaviors than Display/threat behaviors. Discovering that Pursuits were used significantly more during interspecific aggression, and that Contacts were not used significantly less than the Displays when spotted dolphins fought the bottlenose dolphins suggests that spotted dolphins use more energy during interspecific aggression. When individuals put more energy into an aggressive interaction, as it appears the spotted dolphins are doing during aggressive encounters with bottlenose dolphins, it suggests that a valuable resource is at stake. The reasons for interspecific aggression may include competition for food, territory, or mate access, as is found in other mammalian species.

\section{Possible Explanations for Differences}

When two closely related species interact aggressively they are likely competing for some kind of resource: food, space, or perhaps mating opportunities. During the day, spotted dolphins and bottlenose dolphins do not seem to be competing for food resources. Malinowski (2011) found that bottlenose dolphins foraged more often in deeper waters than the spotted dolphins and their primary prey items differed during the day. Spotted dolphins also do not seem to be defending a specific territory. Cusick and Herzing (2014) did not find a significant clustering of interspecific aggressive encounters within our study site, suggesting that there is no physical boundary that separates bottlenose and spotted dolphin territories.

One possibility for the differences in aggressive style could result from spotted dolphins competing against the larger bottlenose dolphins for mating opportunities with females. Male bottlenose dolphins are roughly one meter larger than male spotted dolphins. Herzing and Elliser (2013) have observed copulations between both species and have observed some suspected hybrids over the years (Herzing et al., 2003) but genetic confirmation is still underway. Bottlenose dolphins are well known to hybridize with many other cetacean species both in captivity (Berube, 2002) and in the wild (Acevedo- 
Gutiérrez et al., 2005; Herzing et al., 2003), which strengthens the possibility of hybridization between these two species. During this study, sexually mature females were present during both types of aggression. However, these females were not around significantly more during intraspecific aggression (Volker, 2016). Aggression is often used as a way for males to prevent other males from mating with an estrus female (Lindenfors \& Tullberg, 2011). Thus, male Atlantic spotted dolphins could be using the more costly behaviors to deter the larger bottlenose dolphins during mating attempts with spotted dolphin females or during other competitive activities.

Aside from size being a factor during interspecific aggression, bottlenose dolphins are known to sexually harass the spotted dolphins. Male bottlenose dolphins sexually harass male spotted dolphins by side-mounting them during aggression. Sometimes more than one bottlenose dolphin male side-mounts a single spotted dolphin male at the same time, leaving the spotted dolphins at both a size and number disadvantage. Both synchronization (Cusick \& Herzing, 2014) and sheer numbers (Herzing \& Johnson, 1997) aid the spotted dolphins during interspecific aggression. Using more energy consuming behaviors may just be another part of the puzzle in deciphering how the spotted dolphins are able to contest the bottlenose dolphins.

Lastly, Atlantic spotted dolphins may change their aggressive tactics because of a true interspecies barrier. If the bottlenose dolphins are unfamiliar with some of the subtle meanings in the spotted dolphins' Display Behavioral Events, then the specific messages the spotted dolphins try to convey through the individual Display Behavioral Events may not be fully understood. Even though bottlenose dolphins use some of the same Display Behavioral Events as the spotted dolphins (Connor et al., 1992; Coscarella \& Crespo, 2010; Cotter et al., 2012; Parsons et al., 2003; Wedekin et al., 2004), there may be subtle differences in the Display Behavioral Events themselves or in the messages they are meant to convey and thus are not as efficient to use when fighting a different species. The spotted dolphins could then use more overt Pursuit behaviors to compensate. The intent of a Pursuit behavior may be more universal in the delphinid world and more easily understood. However, a few big questions still remain: 1) at what threshold does interspecific communication breakdown and 2) to what extent are cross-species signals understood?

Overall, the Atlantic spotted dolphins may need to expend more energy and risk more when fighting the bottlenose dolphins for a few different reasons. They may need to 1) defend their females more rigorously from the larger male bottlenose dolphins so that they do not lose reproductive opportunities, 2) use more energy and more overt behaviors to defend themselves against the larger bottlenose who are sexually harassing them, and 3) they may have to revert to more overt Pursuit behaviors to effectively communicate during interspecies aggression.

\section{Conclusion}

This study examined the aggressive behaviors performed by groups of male Atlantic spotted dolphins underwater during both intraspecific aggression and interspecific aggression with bottlenose dolphins. During interspecific aggression the spotted dolphins used more Pursuit behaviors and did not use the Contact Behavioral Type significantly less than the Display Behavioral Type. This suggests that Atlantic spotted dolphin groups use more energetically costly behaviors during aggressive encounters with the larger bottlenose dolphins. They may recognize the bottlenose dolphins as a different species and change their behaviors accordingly, demonstrating behavioral plasticity (Relyea, 2001). Evidence of behavioral plasticity shows that dolphins can learn and alter their behaviors based on stimuli in their environment, including the possibility of species overlap, as communities are forced into new habitats as a result of climate change.

\section{Acknowledgments}

This research was conducted with the Wild Dolphin Project in the Bahamas under the Bahamas Department of Agriculture and Marine Resources. I would like to thank my committee members, Dr. Colin Hughes and Dr. Kate Detwiler for the guidance they provided during my master's thesis. A special 
thank you to all of my lab mates at the Wild Dolphin Project: B. Augliere, A. Myers, N. Skrzypczak, and S. Kuhn. Thank you to A. Myers for putting her research on hold to serve as my second observer for interrater reliability analysis. Also, a special thank you to Amy Hartl for help with my statistical analyses. Last but not least, a thank you to the Wild Dolphin Project Captain, crew, funders, and supporters. Their support and funding have allowed the Wild Dolphin Project to continue to gather valuable information on these two sympatric species of dolphins.

\section{References}

Acevedo-Gutiérrez, A., DiBerardinis, A., Larkin, S., Larkin, K., \& Forestell, P. (2005). Social interactions between tucuxis and bottlenose dolphins in Gandoca-Manzanillo, Costa Rica. Latin American Journal of Aquatic Mammals, 4, 49-54.

Akçay, Ç. L., Tom, M. E., Campbell, S. E., \& Beecher, M. D. (2013). Song type matching is an honest early threat signal in a hierarchical animal communication system. Proceedings of the Royal Society B: Biological Sciences, 280, 20122517.

Arnold, K. E. (2000). Group mobbing behaviour and nest defence in a cooperatively breeding Australian bird. Ethology, 106, 385-393.

Au, W. W., \& Herzing, D. L. (2003). Echolocation signals of wild Atlantic spotted dolphin (Stenella frontalis). The Journal of the Acoustical Society of America, 113, 598-604.

Bender, C. E., Herzing, D. L., \& Bjorklund, D. F. (2009). Evidence of teaching in Atlantic spotted dolphins (Stenella frontalis) by mother dolphins foraging in the presence of their calves. Animal Cognition, 12, 43-53.

Berube, M. (2002). Hybridism. In W. F. Perrin, B. Wursig, \& J. G. M. Thewissen (Eds.), Encyclopedia of marine mammals (pp. 596-600). Academic Press.

Boesch, C., \& Boesch-Achermann, H. (2000). The chimpanzees of the Taï Forest: Behavioural ecology and evolution. Oxford University Press.

Bützler, W. (1974). Aggressive and reproductive behaviour, social rank hierarchy and activity rhythms in the Red deer (Cervus elaphus L.). Zeitschrift für Tierpsychologie, Suppl. 16, 1-80. (In German)

Byrne, R. W., \& da Cunha, R. G. T. (2006). Roars of black howler monkeys (Alouatta caraya): Evidence for a function in inter-group spacing. Behaviour, 143, 1169-1199.

Clutton-Brock, T. H., Albon, S. D., Gibson, R. M., \& Guinness, F. E. (1979). The logical stag: Adaptive aspects of fighting in red deer (Cervus elaphus L.). Animal Behaviour, 27, 211-225.

Connor, R. C., Smolker, R. A., \& Richards, A. F. (1992). Two levels of alliance formation among male bottlenose dolphins (Tursiops sp.). Proceedings of the National Academy of Sciences, 89, 987-990.

Connor, R. C., Watson-Capps, J. J., Sargeant, B. L., Scott, E. M., \& Mann, J. (2005). Aggression in bottlenose dolphins: Evidence for sexual coercion, male-male competition, and female tolerance through analysis of tooth-rake marks and behaviour. Behaviour, 142, 21-44.

Coscarella, M. A., \& Crespo, E. A. (2010). Feeding aggregation and aggressive interaction between bottlenose (Tursiops truncatus) and Commerson's dolphins (Cephalorhynchus commersonii) in Patagonia, Argentina. Journal of Ethology, 28, 183-187.

Cotter, M. P., Maldini, D., \& Jefferson, T. A. (2012). "Porpicide" in California: Killing of harbor porpoises (Phocoena phocoena) by coastal bottlenose dolphins (Tursiops truncatus). Marine Mammal Science, 28, E1-E15.

Cullen, J. M. (1966). E. Ritualization of animal activities in relation to phylogeny, speciation and ecology: Reduction of ambiguity through ritualization. Philosophical Transactions of the Royal Society of London. Series B, Biological Sciences, 251, 363-374.

Cusick, J. A., \& Herzing, D. L. (2014). The dynamic of aggression: How individual and group factors affect the long-term interspecific aggression between two sympatric species of dolphin. Ethology, 120, 287-303.

Dow, D. D. (1977). Indiscriminate interspecific aggression leading to almost sole occupancy of space by a single species of bird. Emu-Austral Ornithology, 77, 115-121.

Dow, D. D. (1979). Agonistic and spacing behaviour of the Noisy Miner Manorina melanocephala, a communally breeding honeyeater. Ibis, 121, 423-436.

Elliser, C. R., \& Herzing, D. L. (2015). Long-term interspecies association patterns of Atlantic bottlenose dolphins, Tursiops truncatus, and Atlantic spotted dolphins, Stenella frontalis, in the Bahamas. Marine Mammal Science, 32, 38-56. 
Ewald, P. W., \& Bransfield, R. J. (1987). Territory quality and territorial behavior in two sympatric species of hummingbirds. Behavioral Ecology and Sociobiology, 20, 285-293.

Geist, V. (1965). On the rutting behavior of the mountain goat. Journal of Mammalogy, 45, 551-568.

Glova, G. J. (1986). Interaction for food and space between experimental populations of juvenile coho salmon (Oncorhynchus kisutch) and coastal cutthroat trout (Salmo clarki) in a laboratory stream. Hydrobiologia, 131, 155-168.

Grether, G. F., Anderson, C. N., Drury, J. P., Kirschel, A. N., Losin, N., Okamoto, K., \& Peiman, K. S. (2013). The evolutionary consequences of interspecific aggression. Annals of the New York Academy of Sciences, 1289, 48-68.

Heinsohn, R. (1997). Group territoriality in two populations of African lions. Animal Behaviour,53, $1143-1147$.

Herzing, D. L. (1996). Vocalizations and associated underwater behavior of free-ranging Atlantic spotted dolphins, Stenella frontalis and bottlenose dolphins, Tursiops truncatus. Aquatic Mammals, 22, 61-80.

Herzing, D. L. (1997). The life history of free-ranging Atlantic spotted dolphins (Stenella frontalis): Age classes, color phases, and female reproduction. Marine Mammal Science, 13 576-595.

Herzing, D. L. (2000). Acoustics and social behavior of wild dolphins: Implications for a sound society. In W. W. L. $\mathrm{Au}$, R. R. Fay, \& A. N. Popper (Eds.) Hearing by whales and dolphins (pp. 225-272). Springer.

Herzing, D. L. (2004). Social and nonsocial uses of echolocation in free-ranging Stenella frontalis and Tursiops truncatus. In J. Thomas (Ed.), Advances in the study of echolocation in bats and dolphins (pp. 404-410). University of Chicago Press.

Herzing, D. L., \& Brunnick, B. J. (1997). Coefficients of association of reproductively active female Atlantic spotted dolphins, Stenella frontalis. Aquatic Mammals, 23, 155-162.

Herzing, D. L., \& Elliser, C. R. (2013). Directionality of sexual activities during mixed-species encounters between Atlantic spotted dolphins (Stenella frontalis) and bottlenose dolphins (Tursiops truncatus). International Journal of Comparative Psychology, 26, 124-134.

Herzing, D. L., \& Johnson, C. M. (1997). Interspecific interactions between Atlantic spotted dolphins (Stenella frontalis) and bottlenose dolphins (Tursiops truncatus) in the Bahamas, 1985-1995. AquaticMammals, 23, 85-99.

Herzing, D. L., Moewe, K., \& Brunnick, B. J. (2003). Interspecies interactions between Atlantic spotted dolphins, Stenella frontalis and bottlenose dolphins, Tursiops truncatus, on Great Bahama Bank, Bahamas. Aquatic Mammals, 29, 335-341.

Huber, R., \& Brennan, P. (2011). Aggression. In R. Huber, D. L. Bannasch, \& P. Brennan (Eds.), Advances in genetics (pp. 1-6). Elsevier.

Kaburu, S. S., Inoue, S., \& Newton-Fisher, N. E. (2013). Death of the alpha: Within community lethal violence among chimpanzees of the Mahale Mountains National Park. American Journal of Primatology, 75 789797.

Kurimoto, M. (2003). Behavioural observations of bottlenose dolphins towards two dead conspecifics. Aquatic Mammals, 29, 108-116.

Lindenfors, P., \& Tullberg, B. S. (2011). Evolutionary aspects of aggression: The importance of sexual selection. In R. Huber, D.L. Bannasch, \& P. Brennan (Eds.) Advances in genetics (pp. 7-22). Elsevier.

LeDuc, R. G., Perrin, W. F., \& Dizon, A. E. (1999). Phylogenetic relationships among the delphinid cetaceans based on full cytochrome b sequences. Marine Mammal Science, 15, 619-648.

Malinowski, C. R. (2011). Nutrition and habitat driven foraging of wild dolphins in the Bahamas: A recipe for prey use [unpublished master's thesis]. Florida Atlantic University.

Martin, P. R., \& Bateson, P. P. (2007). Measuring behaviour: An introductory guide (3 ${ }^{\text {rd }}$ ed). Cambridge University Press.

Mitani, J. C., Watts, D. P., \& Amsler, S. J. (2010). Lethal intergroup aggression leads to territorial expansion in wild chimpanzees. Current Biology, 20, R507-R508.

Muller, M. N. (2002). Agonistic relations among Kanyawara chimpanzees. In C. Boesch, G. Hohmann, \& L. Marchant (Eds.), Behavioural diversity in chimpanzees and bonobos (pp. 112-124). Cambridge University Press.

National Oceanic and Atmospheric Administration (NOAA). (n.d.). Atlantic spotted dolphin. US Department of Commerce. Retrieved August 6, 2020, from https://www.fisheries.noaa.gov/species/atlantic-spotted-dolphin

National Oceanic and Atmospheric Administration (NOAA). (n.d.). Common bottlenose dolphin. US Department of Commerce. Retrieved August 6, 2020, from https://www.fisheries.noaa.gov/species/common-bottlenosedolphin 
Parsons, K. M., Durban, J. W., \& Claridge, D. E. (2003). Male-male aggression renders bottlenose dolphin (Tursiops truncatus) unconscious. Aquatic Mammals, 29, 360-362.

Psarakos, S., Herzing, D. L., \& Marten, K. (2003). Mixed-species associations between pantropical spotted dolphins (Stenella attenuata) and Hawaiian spinner dolphins (Stenella longitrostris) off Oahu, Hawaii. Aquatic Mammals, 29, 390-395.

Relyea, R. A. (2001). Morphological and behavioral plasticity of larval anurans in response to different predators. Ecology, 82, 523-540.

Robinson, K. P. (2014). Agonistic intraspecific behavior in free-ranging bottlenose dolphins: Calf-directed aggression and infanticidal tendencies by adult males. Marine Mammal Science, 30, 381-388.

Rogers, C. A., Brunnick, B. J., Herzing, D. L., \& Baldwin, J. D. (2004). The social structure of bottlenose dolphins, Tursiops truncatus, in the Bahamas. Marine Mammal Science, 20, 688-708.

Shane, S. H. (1996). Relationship between pilot whales and Risso's dolphins at Santa Catalina Island, California, USA. Marine Ecology Progress Series, 123, 5-11.

Slotow, R. (1996). Aggression in white-crowned sparrows: Effects of distance from cover and group size. The Condor, 98, 245-252.

The Observer XT [Computer software]. 2012. Retrieved from http://www.noldus.com/animal-behaviorresearch/ products/the-observer-xt

Van Rhijn, J. G. (1980). Communication by agonistic displays: A discussion. Behaviour, 74, 284-293.

Volker, C. L. (2016). Aggressive behaviors of adult male Atlantic spotted dolphins (Stenella Frontalis) during intraspecific and interspecific aggressive interactions (Publication No. FA00004638) [Master's Thesis, Florida Atlantic University]. Florida Atlantic University Digital Library.

Waas, J. R. (1991). The risks and benefits of signalling aggressive motivation: A study of cave dwelling little blue penguins. Behavioral Ecology and Sociobiology, 29, 139-146.

Weaver, A. (2003). Conflict and reconciliation in captive bottlenose dolphins, Tursiops truncatus. Marine Mammal Science, 19, 836-845.

Wedekin, L. L., Daura-Jorge, F. G., \& Simões-Lopes, P. C. (2004). An aggressive interaction between bottlenose dolphins (Tursiops truncatus) and estuarine dolphins (Sotalia guianensis) in southern Brazil. Aquatic Mammals, 30, 391-397.

Wilson, M. L., Britton, N. F., \& Franks, N. R. (2002). Chimpanzees and the mathematics of battle. Proceedings of the Royal Society of London. Series B: Biological Sciences, 269, 1107-1112.

Wilson, M. L., \& Wrangham, R. W. (2003). Intergroup relations in chimpanzees. Annual Review of Anthropology, 32, 363-392. 